\title{
CYTOMORPHOLOGICAL ANALYSIS OF LYMPH NODE PATHOLOGY IN A TERTIARY CARE HOSPITAL
}

\author{
Kavitha Duraisamy1, Dhamayanthi Surya Moorthy², Revathi Ramakrishnan ${ }^{3}$
}

${ }^{1}$ Associate Professor, Department of Pathology, Government Theni Medical College, Theni.

${ }^{2}$ Associate Professor, Department of Pathology, Government Theni Medical College, Theni.

${ }^{3}$ Associate Professor, Department of Pathology, Government Theni Medical College, Theni.

\section{ABSTRACT}

\section{BACKGROUND}

Lymph node pathology includes a wide range of diseases, which ranges from inflammatory lesion to lymphoma and metastatic deposits. Even though, the biopsy yields the confirmed diagnosis. FNAC maybe the only test, which gives a preliminary diagnosis, gives idea to further management and treatment in some cases particularly in malignant deposits and chronic granulomatous diseases like tuberculosis. FNAC is an outpatient procedure, which needs minimal manpower and no need of surgical intervention or anaesthesia. In this descriptive study, we analyse the presentations of lymphadenopathy cases in cytology, categorise the diagnosis and compare the FNAC findings with the histopathological diagnosis and assess the efficacy of the FNAC test in lymph node pathology.

\section{MATERIALS AND METHODS}

In this descriptive study, we took FNA cases sent to our Pathology Department with signs of lymph node enlargement. Patients presented with lymph node enlargement in the sites of cervical, axillary, supraclavicular, inguinal and multiple sites were included in this study. Cases were selected from January 2015 to December 2016. Cases with inadequate material and improper staining were excluded. We use 22-23G needle with $10 \mathrm{~mL}$ disposable syringe for aspiration. Smears were made, fixed in isopropyl alcohol and stained with routine $\mathrm{H}$ and $\mathrm{E}$, if necessary Giemsa stains were used. The cytological diagnoses were correlated with histopathological diagnosis. Immunohistochemistry was done in relevant cases to confirm the diagnosis.

\section{RESULTS}

A total no. of 1842 FNAC cases were received in our Pathology Department during the period between January 2015 to December 2016. The age distribution was between 1 year to 80 years. The lymph node enlargement was more common in males than in females. In the cytological cases, certain discrepancies observed with the referring surgeon regarding the diagnosis. Out of 4 cases, 2 were lymphoproliferative disease and 2 cases of metastatic deposits were referred for IHC study. In the IHC study, 4 cases of lymphoproliferative disease were confirmed as NHL and 2 cases of secondary metastatic deposits, which was in discrepancy with clinicians as lymphoma were confirmed by IHC as carcinomatous deposits.

\section{CONCLUSION}

Based on the study, FNAC is the first line of investigation and helpful procedure in the diagnosis of neoplastic and nonneoplastic lesions of the lymph node. FNAC is not only useful in the diagnosis of various lesions of lymph node and also open the gateway for the clinicians in the management of the lymph node pathology.

\section{KEYWORDS}

Lymph Node, FNAC, Histopathology.

HOW TO CITE THIS ARTICLE: Duraisamy K, Moorthy DS, Ramakrishnan R. Cytomorphological analysis of lymph node pathology in a tertiary care hospital. J. Evolution Med. Dent. Sci. 2017;6(73):5211-5216, DOI: 10.14260/Jemds/2017/1132

\section{BACKGROUND}

Lymph node enlargement (lymphadenopathy) is the most common presentation in many neoplastic and nonneoplastic diseases. FNAC is one of the most important screening test in lymph node pathology.

Lymph node pathology includes a wide range of diseases, which ranges from inflammatory lesion to lymphoma and metastatic deposits.

Even though, the biopsy yields the confirmed diagnosis, FNAC maybe the only test, which gives a preliminary

Financial or Other, Competing Interest: None.

Submission 28-07-2017, Peer Review 27-08-2017,

Acceptance 01-08-2017, Published 11-09-2017.

Corresponding Author:

Dr. Dhamayanthi Surya Moorthy,

\#1-1-93/F10, Usilai Road,

Peraiyur, Madurai-625703, Tamilnadu.

E-mail: revathiram67@gmail.com

DOI: $10.14260 /$ jemds $/ 2017 / 1132$ diagnosis, gives idea to further management and treatment in some cases particularly in malignant deposits and chronic granulomatous inflammation like tuberculosis.

Routine use of FNAC can help us to diagnose the types of lymphadenopathies.

Sometimes, lymph node enlargement is the first manifestation of the diseases. In that situations, FNAC will give a clue to identify the primary along with other modality of investigations such as radiological and Immunohistochemical study (IHC).

In this descriptive study, we analysed the presentations of lymphadenopathy cases in cytology, categorise the diagnosis and compared the FNAC findings with the histopathological diagnosis and observed the efficacy of the FNAC test in lymph node pathology. Any discrepancy in the histopathological diagnosis of the lymph node diseases especially in case of lymphoma, the diagnosis was confirmed with the CD markers study. 


\section{MATERIALS AND METHODS}

In this descriptive study, we took FNA cases sent to our Pathology Department with signs of lymph node enlargement. Patients presented with lymph node enlargement in the sites of cervical, axillary, supraclavicular, inguinal and multiple sites were included in this study.

Cases were selected from January 2015 to December 2016. Cases with inadequate materials and improper staining cases were excluded.

Total number of FNAC cases in the two years, which is from January 2015 to December 2016 were 1844 . Among them, 194 cases had the lymph node enlargement were subjected to FNAC. We use 22-23G needle with $10 \mathrm{~mL}$ disposable syringe for aspiration. Smears were made, fixed in isopropyl alcohol and stained with routine $\mathrm{H}$ and $\mathrm{E}$ stains. Clinical details and relevant investigations were documented. Consent were obtained before aspiration.

In the follow up study, node biopsy of all the 194 cytological cases were received. Bits were taken, processed routinely and sections were stained with routine $\mathrm{H}$ and $\mathrm{E}$ stains. The cytological diagnoses were correlated with histopathological diagnosis by the pathologist.

Immunohistochemistry was done in relevant cases to confirm the diagnosis. In cases of unsuspected secondary deposits in the lymph node, primary site was searched by the surgeon by appropriate radiological investigation and confirmed with biopsy from the primary tumour. The lymph node biopsy correlated well with cytological analysis.

\section{RESULTS}

A total number of 1842 FNAC cases were received in our Pathology Department during the period between January 2015 to December 2016 as shown in Table 1.

\begin{tabular}{|c|c|c|c|}
\hline $\begin{array}{c}\text { Duration of } \\
\text { Years }\end{array}$ & $\begin{array}{c}\text { Total No. } \\
\text { of FNAC }\end{array}$ & $\begin{array}{c}\text { FNAC of } \\
\text { Node }\end{array}$ & Percentage \\
\hline January 2015 & 920 & 92 & $10 \%$ \\
\hline December 2016 & 922 & 102 & $11.06 \%$ \\
\hline \multicolumn{2}{|c|}{ Table 1. }
\end{tabular}

Among these, 194 cases were the lymph node enlargement of various sites sent to our department for cytological study preoperatively for the provisional diagnosis. In 194 lymph node enlargements, the site predilections (as in table 2) were cervical, supraclavicular, axillary, inguinal and occipital node enlargement. Cervical node enlargement was seen in 112 cases (\%), supraclavicular node enlargement was in 25 cases (\%), 20 cases were axillary node enlargement ( 5 cases both axillary node enlargement), 12 cases had inguinal node enlargement and occipital node enlargement was in 5 cases. 20 cases show multiple node enlargement.

\begin{tabular}{|c|c|c|}
\hline Site of Node Enlargement & No. of Cases & Percentage \\
\hline Cervical & 112 & $57.73 \%$ \\
\hline Supraclavicular & 25 & $12.89 \%$ \\
\hline Axillary & 20 & $10.31 \%$ \\
\hline Occipital & 5 & $2.6 \%$ \\
\hline Inguinal & 12 & $6.19 \%$ \\
\hline Multiple & 20 & $10.31 \%$ \\
\hline Table 2. Shows the Site Predilection \\
\hline
\end{tabular}

The age distribution was between 1 year to 80 years as shown in Table 3. In children, the most common diagnosis was reactive lymphadenopathy, lymphoma and granulomatous lymphadenopathy. In older age group, the most common cytological diagnosis was secondary deposits and granulomatous lymphadenopathy.

\begin{tabular}{|c|c|c|}
\hline Age in Yrs. & No. of Cases & Percentage \\
\hline $1-10$ & 60 & $30.93 \%$ \\
\hline $11-20$ & 34 & $17.53 \%$ \\
\hline $21-30$ & 33 & $17.01 \%$ \\
\hline $31-40$ & 19 & $9.79 \%$ \\
\hline$>40$ & 48 & $24.74 \%$ \\
\hline \multicolumn{2}{|c|}{ Table 3. Shows the Age Distribution } \\
\hline
\end{tabular}

According to Table 4, in our study, the lymph node enlargement is more common in male than in female.

\begin{tabular}{|c|c|c|}
\hline Sex & No. of Cases & Percentage \\
\hline Male & 113 & $58.25 \%$ \\
\hline Female & 81 & $41.75 \%$ \\
\hline \multicolumn{2}{|c|}{ Table 4. Shows the Sex Predilection } \\
\hline
\end{tabular}

The cytological diagnosis of 194 cases were categorised into-

- Reactive lymphadenitis.

- Granulomatous lymphadenitis.

- Acute nonspecific lymphadenitis.

- Chronic nonspecific lymphadenitis.

- Lymphoma and lymphoproliferative disease.

- Secondary metastatic deposits.

They are shown in Table 5.

\begin{tabular}{|c|c|c|}
\hline Cytological Diagnosis & No. of Cases & Percentage \\
\hline Reactive & 57 & $29.38 \%$ \\
\hline Granulomatous & 72 & $37.11 \%$ \\
\hline Acute nonspecific & 10 & $5.15 \%$ \\
\hline Chronic nonspecific & 13 & $6.70 \%$ \\
\hline Lymphoma & 10 & $5.15 \%$ \\
\hline Lymphoproliferative & 4 & $2.06 \%$ \\
\hline Secondary metastatic deposits & 28 & $14.43 \%$ \\
\hline \multicolumn{2}{|c|}{ Table 5. Show the Cytological Diagnosis } \\
\hline
\end{tabular}

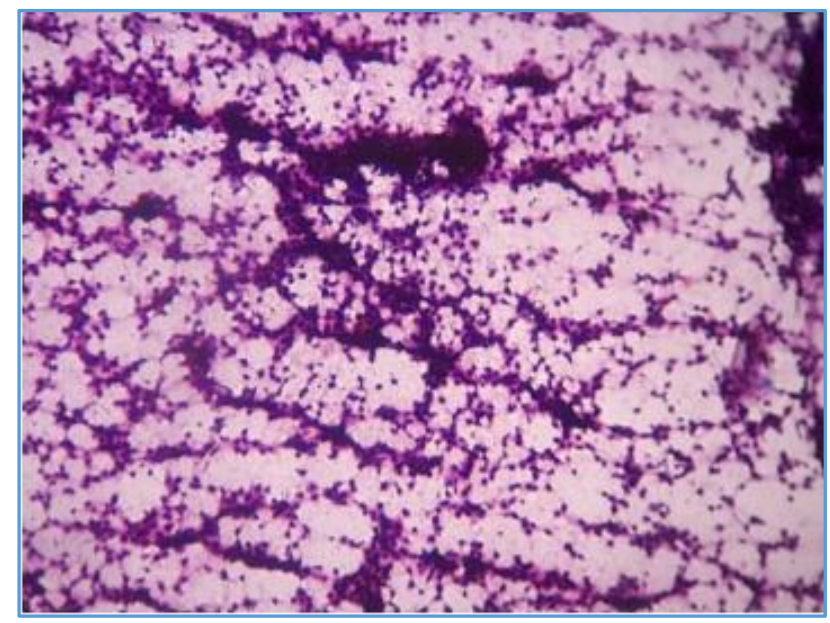

Figure 1. FNAC-10x Power Shows Monomorphic Neoplastic Lymphocytes 


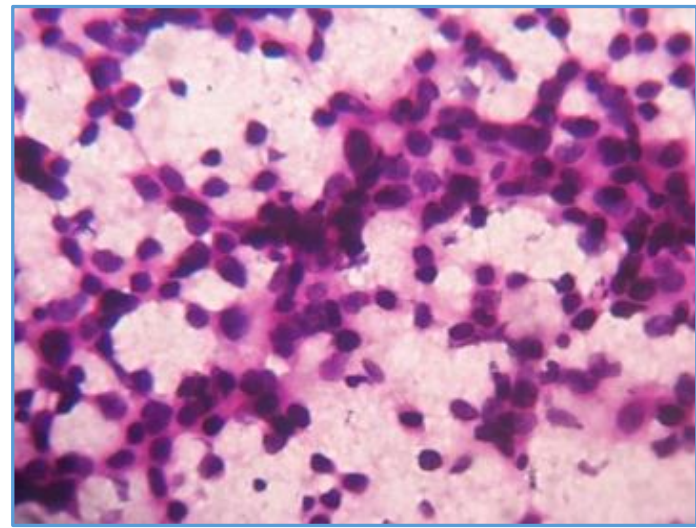

Figure 2. FNAC-40x Power Shows Monomorphic Neoplastic Lymphocytes

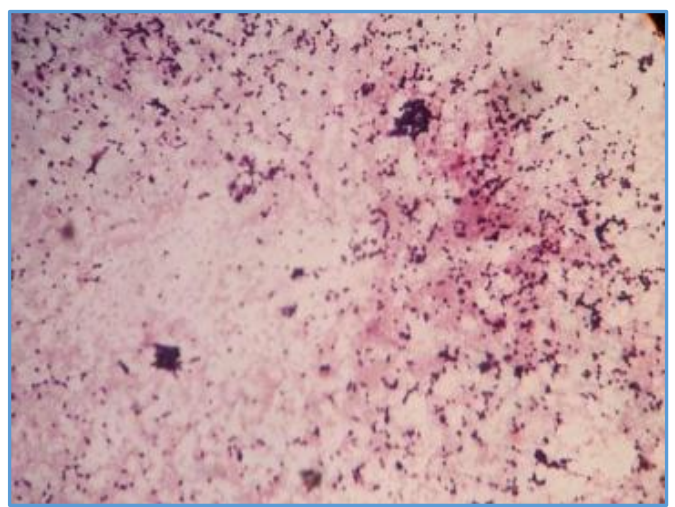

Figure 3. FNAC-10x Power Shows Groups of Pleomorphic Epithelial Cells with Reactive Lymphocytes

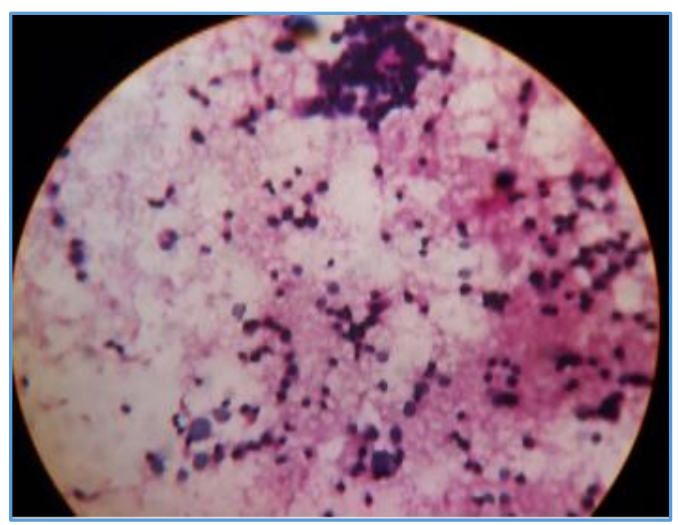

Figure 4. FNAC-40x Power Shows Groups of Pleomorphic Epithelial Cells with Reactive Lymphocytes

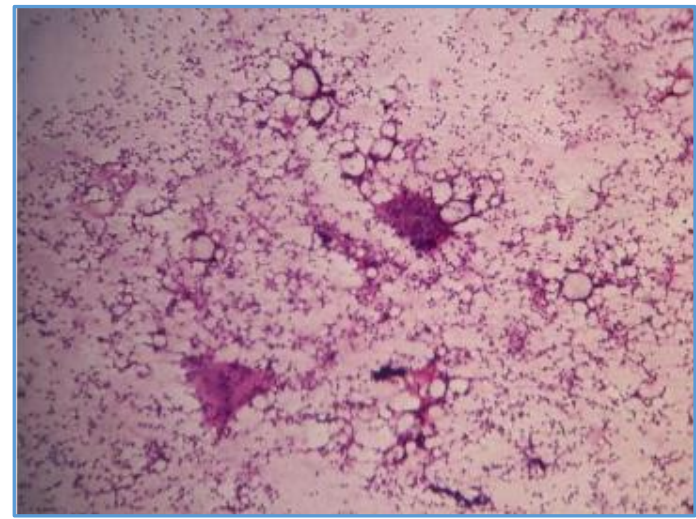

Figure 5. FNAC-10x Power Shows Groups of Epithelioid Cells

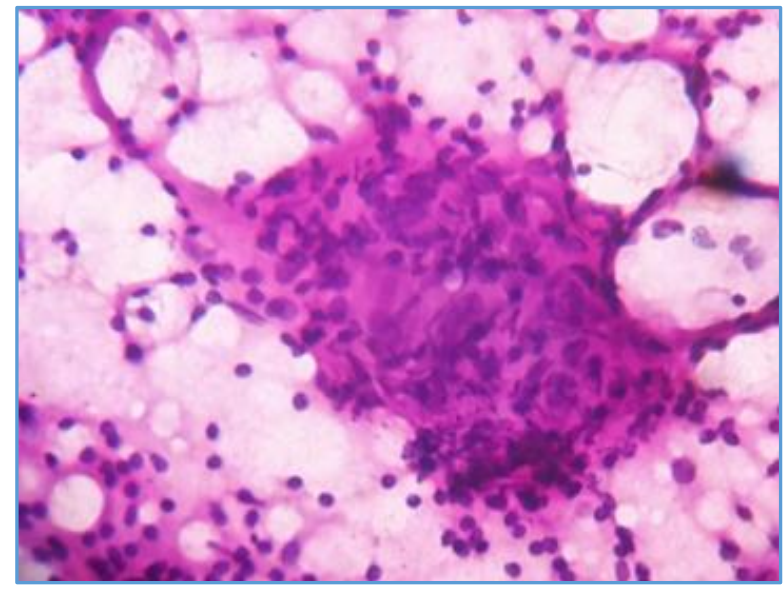

Figure 6. FNAC-40x Power Shows Groups of Epithelioid Cells

194 cytological cases were followed up excision biopsy of the lymph nodes received were subjected to the histopathological examination, which is shown in Table 6. The cytological diagnoses were correlated with histopathological diagnosis for its accuracy as in Table 7.

\begin{tabular}{|c|c|c|c|}
\hline \multicolumn{2}{|c|}{ Histopathological Diagnosis } & No. of Cases & Percentage \\
\hline \multicolumn{2}{|c|}{ Reactive } & 57 & $29.38 \%$ \\
\hline \multicolumn{2}{|c|}{ Granulomatous } & 72 & $37.11 \%$ \\
\hline \multicolumn{2}{|c|}{ Acute nonspecific } & 10 & $5.15 \%$ \\
\hline \multicolumn{2}{|c|}{ Chronic nonspecific } & 13 & $6.705 \%$ \\
\hline \multirow{2}{*}{ Lymphoma } & NHL & 11 & $5.67 \%$ \\
\hline & HL & 3 & $1.55 \%$ \\
\hline \multicolumn{2}{|c|}{ Secondary metastatic deposit } & 28 & $14.43 \%$ \\
\hline \multicolumn{4}{|c|}{ Table 6. Shows Histopathological Diagnosis } \\
\hline
\end{tabular}

In the cytological cases, discrepancies were occurred with the referring surgeon regarding the diagnosis. In this, 4 cases of lymphoproliferative disease and 2 cases of metastatic deposits were referred for IHC study.

In the IHC study, the 4 cases of lymphoproliferative disease were confirmed as NHL and two cases of secondary metastatic deposits, which was in discrepancies with clinicians as lymphoma were confirmed by IHC as carcinomatous deposits as in Table 8.

\begin{tabular}{|c|c|c|c|}
\hline $\begin{array}{l}\text { Cytological } \\
\text { Diagnosis }\end{array}$ & $\begin{array}{l}\text { No. of } \\
\text { Cases }\end{array}$ & $\begin{array}{c}\text { No. of } \\
\text { Cases in } \\
\text { HPE }\end{array}$ & $\begin{array}{c}\text { Histopathological } \\
\text { Diagnosis }\end{array}$ \\
\hline Reactive & 57 & 57 & Reactive \\
\hline Granulomatous & 72 & 72 & Granulomatous \\
\hline Acute nonspecific & 10 & 10 & Acute nonspecific \\
\hline Chronic nonspecific & 13 & 13 & Chronic nonspecific \\
\hline \multirow[t]{2}{*}{ Lymphoma } & 10 & 7 & NHL \\
\hline & & 3 & HL \\
\hline Lymphoproliferative & 4 & 4 & NHL \\
\hline $\begin{array}{c}\text { Secondary metastatic } \\
\text { deposits }\end{array}$ & 28 & 28 & $\begin{array}{c}\text { Secondary } \\
\text { metastatic deposit }\end{array}$ \\
\hline \multicolumn{4}{|c|}{$\begin{array}{c}\text { Table 7. Shows Correlation of FNAC } \\
\text { with Histopathological Study }\end{array}$} \\
\hline
\end{tabular}




\begin{tabular}{|c|c|c|c|}
\hline $\begin{array}{c}\text { Cytological } \\
\text { Diagnosis }\end{array}$ & $\begin{array}{c}\text { No. of } \\
\text { Cases }\end{array}$ & $\begin{array}{c}\text { Histopathological } \\
\text { Diagnosis }\end{array}$ & $\begin{array}{c}\text { IHC } \\
\text { Results }\end{array}$ \\
\hline $\begin{array}{c}\text { Lympho- } \\
\text { proliferative }\end{array}$ & 4 & NHL & $\begin{array}{c}\text { CD45+, } \\
\text { CD19+, } \\
\text { CD20+ }\end{array}$ \\
\hline Secondary deposits & 2 & $\begin{array}{c}\text { Secondary } \\
\text { deposits }\end{array}$ & $\begin{array}{c}\text { Cytokeratin } \\
+, \text { EMA+ }\end{array}$ \\
\hline Lymphoma & 10 & NHL- 7 cases & $\begin{array}{c}\text { CD45+, } \\
\text { CD19+, } \\
\text { CD20+ }\end{array}$ \\
\hline \multicolumn{2}{|c|}{ Table 8. Shows the IHC Study } \\
\hline \multicolumn{3}{|c|}{} \\
\hline \multicolumn{2}{|c|}{} \\
\hline
\end{tabular}

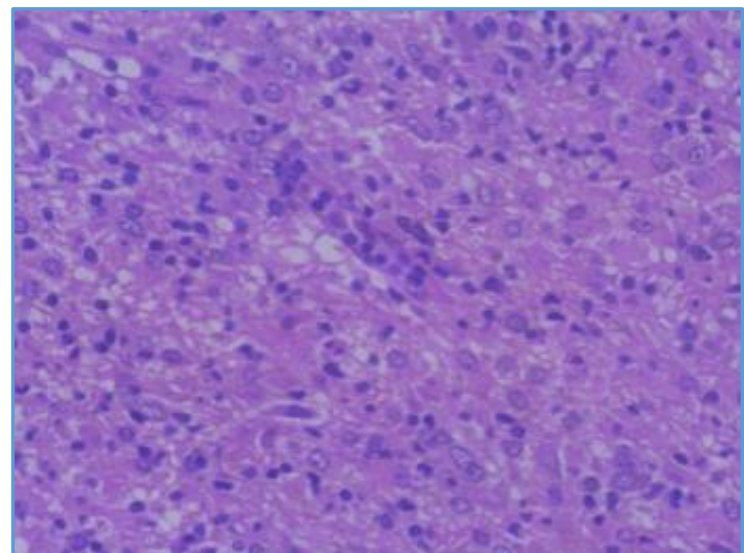

Figure 7. HPE-Non-Hodgkin Lymphoma

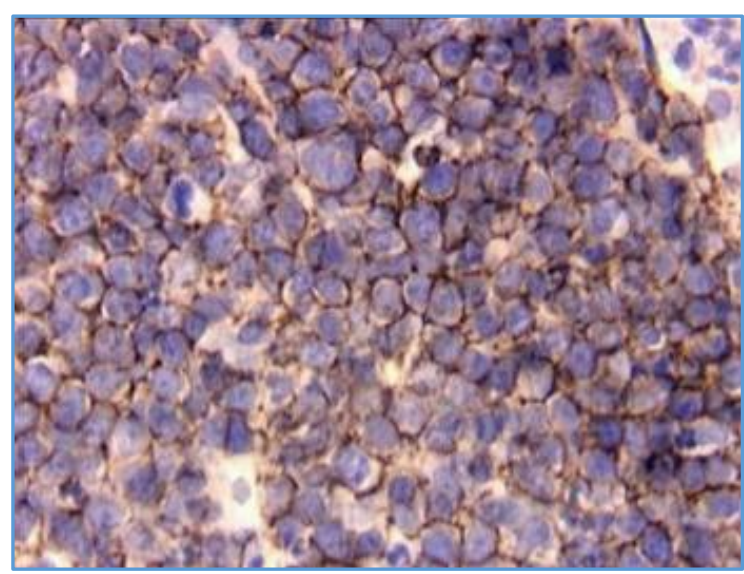

Figure 8. IHC-Non-Hodgkin Lymphoma-CD 45+

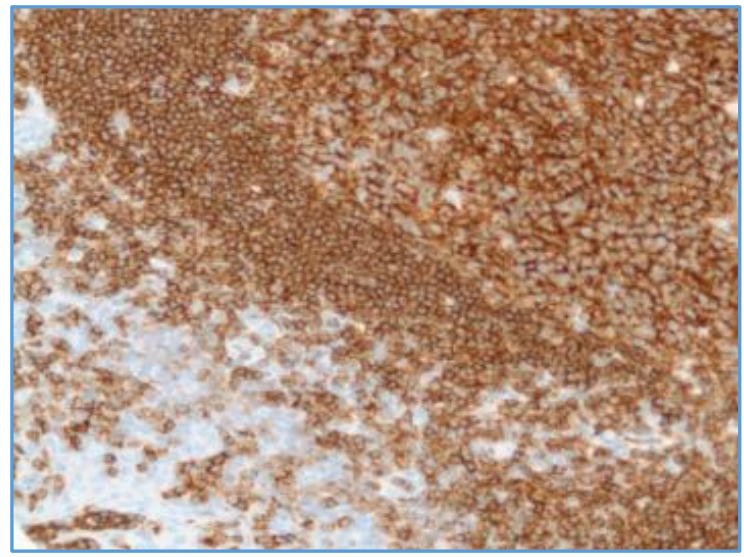

Figure 9. IHC-Non-Hodgkin Lymphoma-CD 19+

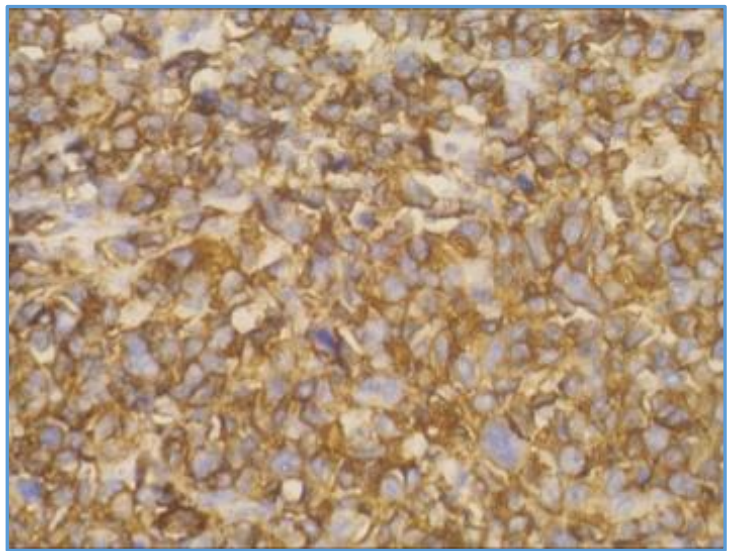

Figure 10. IHC-Non-Hodgkin Lymphoma-CD 20+

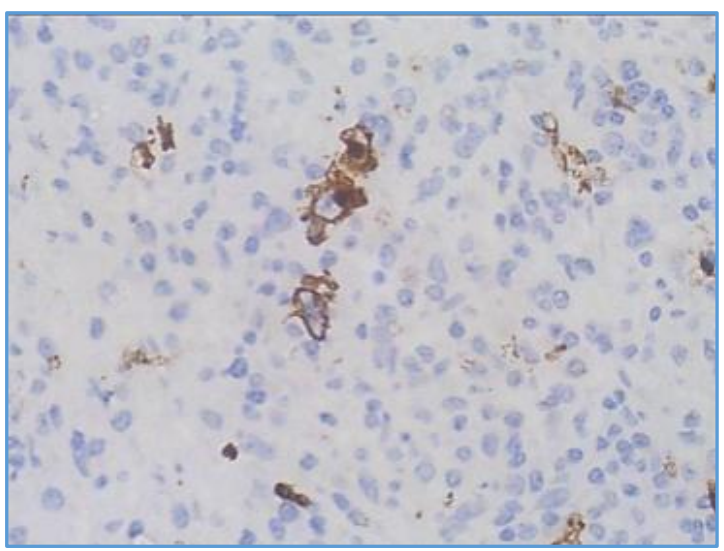

Figure 11. Hodgkin Lymphoma- CD15+

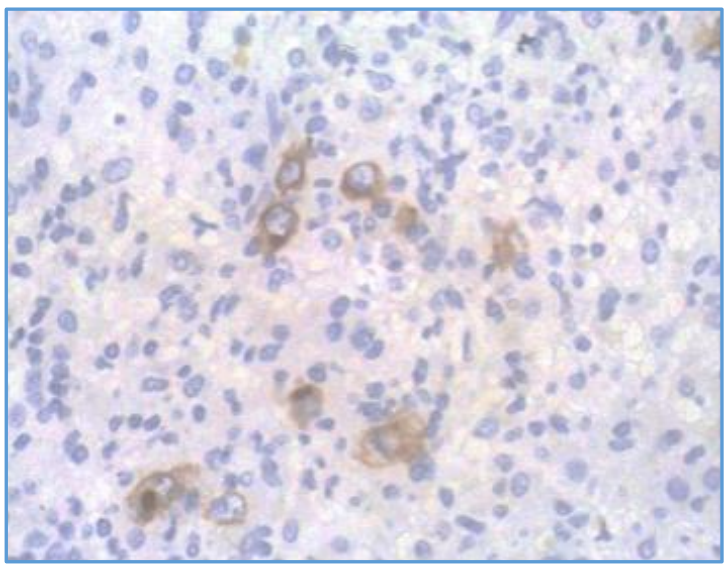

Figure 12. Hodgkin Lymphoma- CD 30+

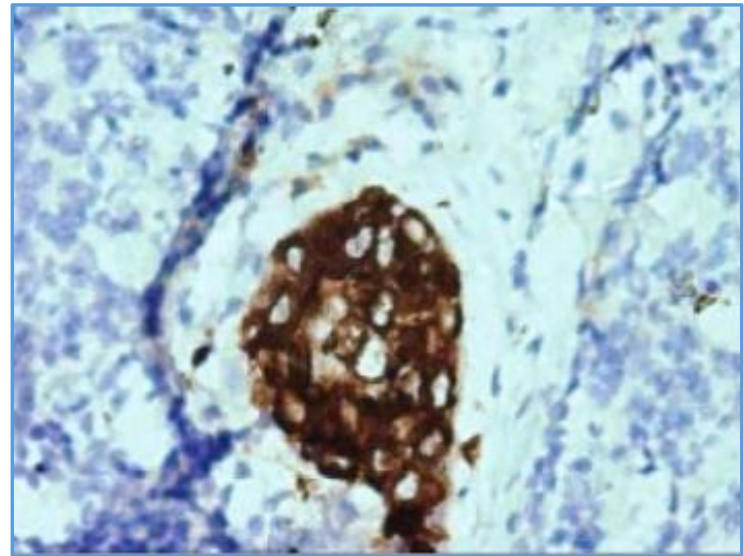

Figure 13. EMA + in Lymph Node 


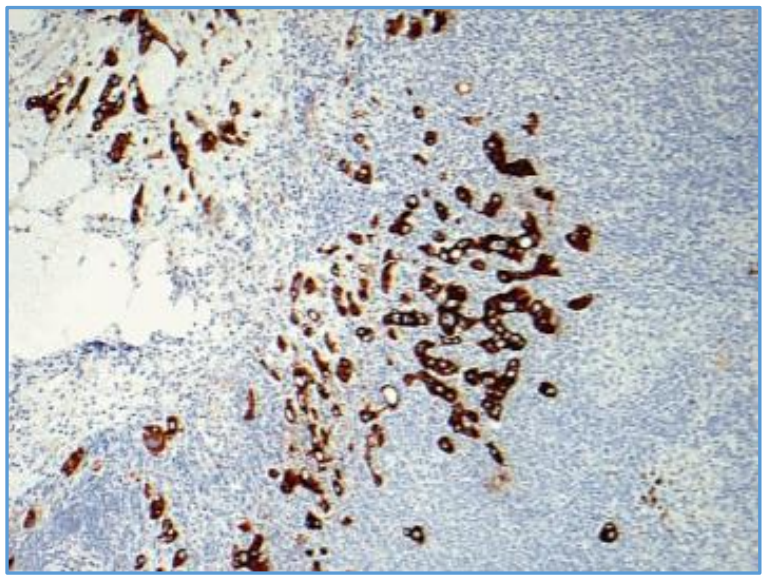

Figure 14. Cytokeratin + in Lymph Node

\section{DISCUSSION}

A study of 194 patients with signs of lymph node enlargement were sent to our Pathology Department for FNAC for preoperative provisional diagnosis.

FNAC is the most important first line investigation to give a provisional diagnosis in the management of lymph node pathology. As lymph node pathology includes vast area of diagnosis, exact correct diagnosis is very difficult even by the eminent pathologist in lymph node enlargement.1,2

Hence, initial diagnosis opens the gate to physician and surgeon in the management of the lymph node enlargement patients.

In our study, lymph node enlargement was common in male than in female. This male predilection is similar to the study conducted by Hirachand et al (2009), Sumit Giri et al (2012) and Adhikari et al (2011) had male preponderance. Whereas in the study by Tariq Mohammed Abdul Nasar et al (2016), which had females preponderance.3,4

The age group was between 7 years to 80 years old. Lymph node enlargement was more in 1 to 10 yrs. (60 patients, $30.93 \%$ ) of age group. 5,6 This is similar to the study conducted by Anno R Wilkinson, Sadhana D, Mahoreand Sabiha A, whereas in the study of Pandit AA et al (51.05\%), Gupta et al (1991) (52.26\%) were in the age group of 0-20 years.7,8,9

The most common site involved in our study is the cervical node, which is $57.73 \%$. This is similar to the study by Hirachand et al (2009) (50.76\%), Guru et al (2009) (78.76\%), Amit et al (2013) (81\%) and also study by Mohammed Abdul Nasar et al (2016) (60\%).10,11

In the cytological diagnosis, granulomatous lymphadenitis is the most common (37.11\%), followed by reactive lymphadenitis (29.38\%) and metastatic deposits were the third most common $14.43 \%$ (28 cases). ${ }^{12,13,14}$

Percentage of metastatic deposits was similar to the study by Mohammed Abdul Nasar et al (2016) (14\%), and in other studies, it was $6 \%$ in A H Khan et al, $21.89 \%$ in Sumit Giri et al, 22.6\% in Anastasio Serrano et al. ${ }^{15,16}$

Lymphomas were $5.15 \%$ in the present study and it was similar to the study by Mohammed Abdul Nasar et al (2016) (5\%) and other studies were 2\% in A H Khan et al and $2.7 \%$ in Sumit Giri et al and it was higher in Anastasio Serrano et al (9\%).

Among the 10 cases of the cytological diagnosis of lymphoma, 7 cases were reported as non-Hodgkin's lymphoma and 3 cases were reported as Hodgkin's lymphoma in the histopathological examination and also showed positivity for CD45, CD19 and CD20 by NHL and CD15, CD30 positivity by HL in IHC study. ${ }^{17}$

In our study, $29.38 \%$ cases were diagnosed to be having reactive lymphadenitis. This is similar to the study by A H Khan et al (2011) 28\% and other study by Hirachand et al (2009) at 41.5\% and Sumit Giri et al (2012) 34.6\%. Guru et al (2009) had incidence of $46.32 \%$ and in Mohammed Abdul Nasar et al (2016) $58.4 \%$ cases. ${ }^{18,19}$

In our study, 4 cases of lymphoproliferative disease in the cytological diagnosis showed the features of NHL in the histopathological examination and also showed positive for CD45, CD19 and CD20 in IHC study.

In the present study, Hodgkin's lymphoma was reported in $1 \%$ cases and non-Hodgkin's lymphoma in $4 \%$ cases. This correlates well with Mohammed Abdul Nasar et al (2016), who reported $4 \%$ of cases of NHL and 1\% of HL, Sumit Giri et al (2012) who reported $1.08 \%$ cases of Hodgkin's lymphoma. Nesreen et al (2011) and Sumyra et al (2012) reported 2.6\% and $2 \%$ of cases of Hodgkin's lymphoma respectively, which are slightly higher than the present study. In the case of NHL, Sumit Giri et al reported much lesser percentage of cases at 1.62\%, whereas Nesreen et al (2011) 16 and Sumyra et al (2012) 15 reported a higher percentage of NHL cases at 5.7\% and $6.5 \%$, respectively.

In the present study, there were 57 cases of reactive lymphadenitis and 72 cases of granulomatous lymphadenitis, which were correlating with both FNAC and HPE yielding a correlation rate of $100 \%$. Adhikari et al (2011) 10 reported a $100 \%$ correlation rate, whereas other studies had a lower correlation rate than the present study, i.e. Nesreen et al (2011) 16 and Sumyra et al (2012) 15 58\% and 76.78\%, respectively. Sumit Giri et al (2012) 9 correlated only 2 cases of reactive lymphadenitis out of 6 leading to $33.3 \%$ correlation rate. In the study by Mohammed Abdul Nasar et al (2016), 20 out of 21 cases of granulomatous lymphadenitis correlated well with both FNAC and HPE (95\%) correlation rate.

In this study, similar to Adhikari et al (2011) 10 and Nesreen et al (2011) 16 reported 100\% correlation rate of metastatic deposits. Sumyra et al (2012) 15 reported a slightly lower correlation rate at $99 \%$ and $96 \%$, respectively. In the present study, all the cases correlated well yielding a $100 \%$ correlation rate.

The correlation rate in all cases reported was $100 \%$ and this is similar to the study by Mohammed Abdul Nasar et al (2016).

\section{CONCLUSION}

Based on the study, FNAC is the first line of investigations and helpful procedure in the diagnosis of neoplastic and nonneoplastic lesions of the lymph node.

FNAC is not only useful in the diagnosis of various lesions of lymph node and also open the gateway for the clinicians in the management of the lymph node pathology especially in case of lymphoma. It is also helpful by correlating with the histopathological examination and by confirmation with the IHC studies to give better treatment in the follow up of cases after chemotherapy and in the diagnosis of secondary deposit cases. 


\section{REFERENCES}

[1] Shoog L. Torsten low hagen and edina taani: lymph nodes. In Winfred Grey: diagnostic cytopathology, Hongkong. Churchill Livingstone 1995:479-526.

[2] Sheik MM, Ansari Z, Ahmed P, et al. Tuberculous lymphadenopathy in children. India Pediatr 1981;18:293-7.

[3] Nayak S, Mani R, Kavatkar AN, et al. Fine needle aspiration cytology in lymphadenopathy of HIV positive patients. Diagn Cytopathol 2003;29(3):146-8.

[4] Saboorian MH, Ashfaq R. The use of fine needle aspiration biopsy in the evaluation of lymphadenopathy. Semin Diagn Pathol 2001;18(2):110-23.

[5] Pandit AA, Candes FP, Khubchandini SR. Fine needle aspiration cytology of lymph nodes. Journal of Postgraduage Medicine 1987;33(3):134-6.

[6] Gupta RK, Naran S, Lallu S, et al. The diagnostic value of fine needle aspiration cytology (FNAC) in the assessment of palpable supraclavicular lymph nodes: a study of 218 cases. Cytopathology 2003;14(4):201-7.

[7] Ahmad T, Naeem M, Ahmad S, et al. Fine needle aspiration cytology (FNAC) and neck swellings in the surgical outpatient. J Ayub Med Coll Abbottabad 2008;20(3):30-2.

[8] Hirachand S, Lakhey M, Akhter J, et al. Evaluation of fine needle aspiration cytology of lymph nodes in Kathmandu Medical College, Teaching Hospital, Kathmandu Univ Med J 2009;7(26):139-42.

[9] Giri S, Singh K. Role of FNAC in evaluation of patients with superficial lymphadenopathy. International Journal of Biological and Medical Research 2012;3(4):2475-9.
[10] Adhikari P, Sinha BK, Baskota DK. Comparison of fine needle aspiration cytology and histopathology in diagnosing cervical lymphadenopathies. Australas Med J 2011;4(2):97-9.

[11] Kumarguru BN, Kulkarni MH, Kamakeri NS. FNAC of peripheral lymph nodes in HIV-positive patients. Scientific Medicine 2009;1(2):1-7.

[12] Amit A, Hardik S, Gauravi D. Fine needle aspiration study of lymph node in HIV patients and CD4 count. Int J Res Med 2013;2(2):16-9.

[13] Khan AH, Hayat AS, Baloch GH. Study on the role of fine needle aspiration cytology in cervical lymphadenopathy. World Applied Sciences Journal 2011;12(11):1951-4.

[14] Egea AS, Miguel A, Perez A, et al. Usefulness of light microscopy in lymph node fine needle aspiration biopsy. Acta Cytologica 2002;46(2):364-8.

[15] Qadri SK, Nissar HH, Praveen S, et al. Profile of lymphadenopathy in Kashmir valley: a cytological study. Asian Pac J Cancer Prev 2012;13(8):3621-5.

[16] Hafez NH, Tahoun NS. Reliability of FNAC as a diagnostic tool in cases of cervical lymphadenopathy. Journal of the Egyptian National Cancer Institute 2011;23(3):105-14.

[17] Dasgupta A, Ghosh RN, Poddar AK, et al. Fine needle aspiration cytology of cervical lymphadenopathy with special reference to tuberculosis. J Indian Med Assoc 1994;92(2):44-6.

[18] Patra AK, Nanda BK, Mahapatra BK, et al. Diagnosis of lymphadenopathy by fine needle aspiration cytology. Indian J Pathol Microbiol 1983;26(4):273-8.

[19] Anuradha S, Parthasarathy V. Usefulness of imprint and FNAC in diagnosis of lymphadenopathies and other tumours. Indian J Pathol Microl 1989;32(4):291-6. 